Vickers Electrical Co., Ltd., then discussed the insulation of switchgear. He surveyed the main uses of insulation, for supports, fillers and coverings, and the suitability of available materials for these purposes and, after emphasizing the need for fuller information concerning the long-term stability of materials and the difficulties of obtaining it, concluded by remarking that technically, if not economically, $500-\mathrm{kV}$. switchgear is a feasible proposition.

The final lecture, by Dr. J. S. Forrest, of the Research Laboratories of the British Electricity Authority, was concerned with the testing of insulation in the laboratory, factory and field. He classified the tests in use according to their function and advised on the interpretation of test results; he emphasized the need for constant review of the methods of test directed towards the formulation of a scheme of testing which would reflect the service conditions to be met as faithfully as possible $\mathrm{He}$ remarked that such an approach would assist in improving the present inadequate correlation between laboratory, factory and field tests.

The specialized discussions which followed the individual lectures were supplemented by a general discussion during the final session, when attention was devoted to questions such as the availability of new materials; the inadequacies of the present classification; the much more satisfactory understanding of the electrical mechanisms of dielectric behaviour compared with those governing the physical and mechanical properties, and finally, the desirability of increased and more fundamental attention to materials in courses leading to degrees and national certificates in electrical engineering. Visits were made during the course to the laboratories of the Electrical Research Association and the British Insulated Callender's Cables, Ltd.

\section{BRITISH SCIENTIFIC INSTRUMENT RESEARCH ASSOCIATION OPEN DAYS}

$\mathrm{W}$ ITH whatever feelings one regards the advancing front of science, it is obvious that the operation of new processes and new techniques, which give force to ideas and actions based on them, is maintained and nourished by the development of scientific instruments. These are tools of industry as well as of research. Thus the practice of the art and craft of instrument-making is a key industry, and it is significant that the British Scientific Instrument Research Association was the first of the industrial research associations, being founded in 1918. The laboratories of the Association are situated near Chislehurst in park-like surroundings, and when members and friends were entertained there on the recent open days (November 5 and 6 ) the weather was mild and clement enough to reinforce the pleasure of the occasion.

For thirty years the work of the Association was carried on in a house in Russell Square, London, and was mainly concerned with the manufacturers of optical instruments. This is not the place to report on the vicissitudes and difficulties of the early years, but in the outcome there has been very considerable development. During and since the Second World War the membership has greatly expanded, as has the scope of the experimental work undertaken, and the facilities provided at Chislehurst are comprehensive and impressive. No great powers of observation are required by the visitor to confirm that the Association is an integral part of the scientific instrument-making industry.

Research associations, though having essential similarities, differ markedly from one another in a variety of ways which reflect the character, scope and state of scientific development of the industries which they serve. Some of them are able to concentrate on the behaviour and manipulation of narrow groups of raw materials or types of processes on which their industries depend. In this sense the field may be relatively narrow, or at least the boundaries may be reasonably well defined. The British Scientific Instrument Research Association must have a broader outlook, for it serves an industry which itself serves a great variety of other industries, and to these must be added the Armed Services, universities and scientific establishments of all kinds. In general, of course, testing and instrumentation are subjects on which a considerable contribution is made to individual industries by their respective research organizations, but there remains an extensive region for activity by the Association.

The original and continuing emphasis on optical work was illustrated during the open days by demonstrations of lens grinding and, judging from the interest displayed by visitors, many people were impressed by the speed and accuracy with which this can be accomplished to precise specifications by precision engineering set-ups. The Association has a small glass-making shop (a palette of colour glasses for artificial eye-making was displayed) and has made considerable contributions to the techniques of chemical analysis of optical glasses, as well as to the examination of such glasses by interferometry, polarimetry and microscopy, including the effects of ageing and attack by humid atmospheres, etc.

The utilization of modern synthetic resins in optical cements has evidently been developed with much satisfaction, and there were striking demonstrations of the preparation of polarizing films from suitable synthetics by molecular orientation, and of metallic mirrors, anti-reflexion films, interference filters for visible light, heat filters, etc., dependent on high-vacuum evaporation techniques.

The development of infra-red transparent materials has made a striking advance through the utilization of the fact (known for some time) that mixed crystals of thallium bromide and iodide are transparent to radiations in the region $0 \cdot 5-40 \mu$. The process was demonstrated of growing single crystals in vertical cylindrical crucibles by a progressive freezing of the melt from bottom to top. The material, known as $K R S-5$, can be ground and polished and is chemically stable.

Graticule production may be described as one of the Association's 'specialities'. The methods adopted are mainly photographic in character and were well illustrated, together with the preparation of resolution test-slides for projection lenses.

Relatively recently, with the increasing use of electronic devices, the Association has built up a department well equipped to deal with a variety of electrical problems, exemplified by work on thermionic valves and valve amplifiers, electrometer valves, resistors of low temperature coefficient, magnetic amplifiers, the effects of dust on electrical contacts, etc. By contrast with the apparent complexities of 
electronic work, there was also displayed in another room the success so far achieved in attempting to answer the simply stated question: How can one ensure free movement of mercury drops in sealed glass tubes such as are used in rocker contacts on electrical relays, etc., so as to avoid faulty makeand-break ?

Studies on the gas permeability of thermocouple sheaths, performance specifications for electric ovens, fluid flow of liquids and gases, and the use of pneumatic (air-jet) gauges for observations on the curvature and thickness of lenses, provided further evidence of the wide scope of the Association's activities.

There were many indications of the flexibility of the broad divisional organization of the laboratories, supported by excellent drawing-office and workshop facilities. One learned that all divisions contribute to the information and liaison services, partly by providing background for the Information Department in dealing with technical inquiries, and partly by visits to member firms to study works procedures, to discuss immediate practical problems, and to seek advice about investigations being carried out by the Association. It is noteworthy that heads of divisions and senior staff generally are expected to spend some 20 per cent of their time in such visiting.

It would seem that those member firms which enter into active membership of the British Scientific Instrument Research Association in all its aspects may benefit exceedingly.

\section{ALLEGHENY OBSERVATORY, UNIVERSITY OF PITTSBURG}

A

SHORT account of the origin and development of the Allegheny Observatory of the University of Pittsburg (pp. 12; from the University) has been compiled by Theodora M. Lauterbach, which makes very interesting reading. The appearance of Donati's Comet in $\mathbf{1 8 5 9}$ aroused a new interest in astronomy, and a group of Pittsburg business men soon organized the 'Allegheny 'Telescope Association' and made plans for the purchase of a large telescope. This 13-in. refractor was made by Fitz, of New York, and was installed in the new building complete with dome, on a hill in the old eity of Allegheny which later became part of Pittsburg. In 1867 the Association presented the telescope and building to the Western University of Pennsylvania - now the University of Pittsburgand in the same year Samuel Pierpont Langley went to Pittsburg as professor of astronomy and director of Allegheny Observatory. Under him, and through financial assistance from William Thaw, a Pittsburg industrial leader, the equipment in the Observatory was greatly improved.

John A. Brashear, a former mill-worker, who had shown a wonderful aptitude for making lenses, and who was encouraged in this work by Langley, played a prominent part in the development of the Observatory. When James F. Keeler, who succeeded Langley in 1891, resigned in 1898 to take up the directorship of Lick Observatory, Brashear became temporary acting director until the following year, when F. L. O. Wadsworth took charge. During the latter's period as director, most of his time was devoted to supervising the construction of the buildings and instruments for the new Observatory, and with Brashear's assistance their efforts were rewarded by the laying of the foundation stone in October 1900. In 1912 the new Allegheny Observatory was dedicated and presented to the University of Pittsburg, and Dr. Frank Schlesinger was appointed director.

The account describes the excellent work of Schlesinger and the succeeding directors-Curtis, Jordan and others-and, as the author says at the end of this interesting brochure, "The Observatory's location serves well for uninterrupted research, and it is through research that Allegheny Observatory has helped to make the University of Pittsburg known throughout the world". The publication contains thirteen photographs of directors, instruments, and portions of the Observatory buildings.

\section{NUFFIELD FOUNDATION}

\section{ANNUAL REPORT}

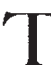
HE seventh report of the Nuffield Foundation covers the year ending March 31, 1952*, and is the third in the current period of the present programme, during which allocations totalling $£ 620,311$ have been made for fundamental research in the United Kingdom; of this, $£ 189,261$ is for biological and $£ 189,950$ for sociological studies, and $£ 110,000$ is reserved for research overseas in the Commonwealth, of which $\mathfrak{4 0 , 1 9 0}$ has been allocated in Australia, $£ 12,712$ in New Zealand and $£ 18,500$ in South Africa. The cost of existing schemes to the end of the quinquennium is estimated at the $£ 498,892$ already set aside, while $£ 112,921$ has been devoted during the current quinquennium to the continuance and extension of projects in medicine, science and the care of old people begun in the first programme. From the Oliver Bird Fund, $£ 114,000$ has been used or reserved for research in rheumatism.

By thus reserving in advance from current income $£ 1,504,849$ of $£ 1,596,042$ allocated in grants for the quinquennium, the Foundation seeks to assure itself of future freedom in the event of any fluctuations either in income or objectives and opportunities. For the advancement of research in the United Kingdom the Foundation has been concerned chiefly to stimulate studies in biology and sociology and, outside these two fields, any other research of real importance or promise which lacks the funds required for its full development. For financing projects of this latter type, the Foundation has set aside a sum which is termed the 'free fund', the use of which is essentially unplanned, and from this fund grants totalling $£ 241,000$ have been allocated during the past year. The greater part of this is to meet the Foundation's commitment to share with the Department of Scientific and Industrial Research the cost of the steerable radio telescope at the Jodrell Bank Experimental Station of the University of Manchester. This grant will avert the postponement of the project because sufficient public funds could not be made available. Grants from the same fund have been made to the University of Cambridge towards the cost of sinking and lining a borehole at or near the geophysical laboratories for experiments and measurements deep into the earth's crust, and towards the construction, during the next five years, of a new and improved high-speed electronic calculating

* Nuffield Foundation. Report for the Year ending 31 March 1952 Pp. 162. (London: Nuffield Foundation, 1952.) 